\title{
AC 2008-288: TEACHING SIX SIGMA IN A COURSE PROJECT
}

\section{Wei Zhan, Texas A\&M University}

Dr. Wei Zhan is an Assistant Professor of Electronics Engineering Technology at Texas A\&M University. Dr. Zhan earned his D.Sc. in Systems Science from Washington University in 1991. From 1991 to 1995 he worked at University of California, San Diego and Wayne State University. From 1995 to 2006, he worked in the automotive industry as a system engineer. In 2006 he joined the Electronics Engineering Technology faculty at Texas A\&M. His research activities include control system theory and applications to industry, system engineering, robust design, modeling, simulation, quality control, and optimization.

\section{Jay Porter, Texas A\&M University}

Jay R. Porter joined the Department of Engineering Technology and Industrial Distribution at Texas A\&M University in 1998 and is currently the Program Director for the Electronics and Telecommunications Programs. He received the BS degree in electrical engineering (1987), the MS degree in physics (1989), and the Ph.D. in electrical engineering (1993) from Texas A\&M University. 


\title{
Teaching Six Sigma in a Course Project
}

\begin{abstract}
This paper discusses the experience of teaching Six Sigma as a course project in a junior level Electronics Engineering Technology course. Instead of using a lecture only style of teaching, the Six Sigma methodology was applied during a course project. Over a period of seven weeks, the students learned and practiced Six Sigma theory and processes. They followed the DMAIC (Define, Measure, Analyze, Improve, Control) process to improve a given design. Six Sigma tools such as Critical to Quality (CTQ), Quality Function Deployment (QFD), Failure Mode Effects and Analysis (FMEA) and Critical Path Method (CPM) were introduced to the students. The business aspect of the product development process was added to the technical design contents to make the project more like a real world experience for the students. A survey conducted after the completion of the project showed the effectiveness of the Six Sigma teaching.
\end{abstract}

\section{Introduction}

The name Six Sigma is a statistics term. Six Sigma ${ }^{1}$ is a structured, disciplined, datadriven methodology/process where the focus is placed on improving business performance using tools with an emphasis on statistical analysis. For any product, it is desirable to reduce the variation of certain measurements as illustrated in Figure 1. A Six Sigma process is one that has 3.4 defects or less per million opportunities. Even though statistics is a major part of the Six Sigma methodology, Six Sigma is more of a design process that can improve the bottom line for corporations rather than just a statistical tool used to reduce product variation.

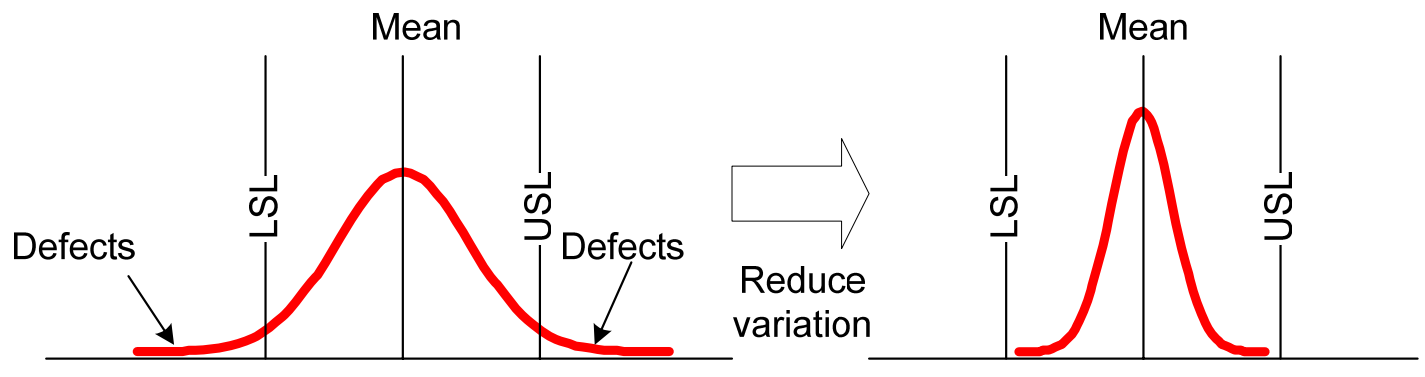

Figure 1. Improving the quality of product by reducing the variation

The Six Sigma process consists of five stages: Define, Measure, Analyze, Improve, and Control (DMAIC) $)^{2}$. The purpose, scope and goals of the project are specified in the Define stage. The process being studied is also identified in this stage. In the Measure stage, a data collection plan is created, and measurement system assessment is conducted. Process, data, and potential root causes are analyzed in the Analyze stage. Solutions are then analyzed, tried out and implemented in the Improve stage. The results are validated and the improved process is standardized in the Control stage.

Six Sigma provides a systematic methodology for solving engineering problems and improving the quality of products. It is much more effective than the trial-and-error method. There are several key aspects of the Six Sigma methodology that distinguish it 
from other engineering methods: it is driven by data; statistical tools are extensively used; and the Voice of Customer (VOC) is emphasized throughout the entire process.

Six Sigma is commonly used by engineers. For many companies in the manufacturing industry and pharmaceutical industry, Six Sigma is considered prerequisite knowledge for the successful engineer. Using Six Sigma can improve the company's bottom line significantly. There are many real-world examples of the effectiveness of Six Sigma. Motorola credits the Six Sigma initiative for saving \$940 million over three years ${ }^{2}$. AlliedSignal (now Honeywell) reported \$1.5 billion in savings in $1997^{2}$.

In academia, Six Sigma is usually taught in Industrial Engineering as a part of a quality control course and some universities offer courses with a focus on Six Sigma ${ }^{3}$. Unfortunately, in most of these cases, the students usually find a non-technical process to improve. While one would expect Six Sigma techniques to be included in all Engineering Technology programs, most Electronic Engineering Technology students do not receive formal education in Six Sigma even though many educators realize the benefit of exposing the students to the process of product quality improvement. However, it is important to teach the students that "Customers don't experience average, they experience variation." By teaching Six Sigma in our Electronic Engineering Technology program, we can reduce the gap between what the students learn in school and what they face in the real world. By adding Six Sigma knowledge to the education the students receive in an Electronic Engineering Technology program, students have a better chance of making a contribution immediately after graduation.

\section{Teaching and Practicing of Six Sigma}

Since Six Sigma is not considered a focus for most Electronic Engineering Technology programs in the United States, it does not make sense to have a separate course on Six Sigma or Quality Control. Students learn best by practicing the Six Sigma methodology over the course of a technical project. They do not need to be experts in Six Sigma or a particular tool; they just need to be exposed to the basic concepts. A program focusing on early exposure of any methodology and repetition in a few courses works the best as discussed by Zhan et $a l^{4}$. Based on these considerations, the Electronics Engineering Technology Program at Texas A\&M University chose to teach Six Sigma processes in a junior-level instrumentation course by applying the Six Sigma methodology to the course project. The students were given a product designed by students in the previous semester. They were asked to follow the Six Sigma DMAIC process to improve the quality of the product.

\subsection{An example of a Six Sigma project}

Instead of the four to eight weeks of lecturing typically used in formal Six Sigma education programs, an example based on an actual Six Sigma project ${ }^{5}$ was presented to the students first so that they had a general understanding of the Six Sigma DMAIC process and some of the tools used before they started their project.

The example presented to the students was concerned the improvement of a Pulse Width Modulation motor speed control algorithm using modeling and simulation. The project goal was identified as reducing the average speed variation by $60 \%$ without any additional cost. In the Define stage, a SIPOC (Supplier Inputs Process Output Customer) graph was constructed to show the interrelationships that could be affected by the motor 
speed control process as illustrated in Figure 2. A Critical to Quality tree was also constructed to understand the customer needs.

\begin{tabular}{|c|c|c|c|c|}
\hline \multicolumn{5}{|c|}{ SIPOC } \\
\hline Supplier & Inputs & Process & Outputs & Customers \\
\hline OEMs & Requirements & \multirow{4}{*}{$\begin{array}{c}\text { Motor } \\
\text { PWM } \\
\text { Control }\end{array}$} & $\begin{array}{l}\text { Motor } \\
\text { durability }\end{array}$ & OEMs \\
\hline NVH group & $\begin{array}{c}\text { Noise, } \\
\text { benchmark }\end{array}$ & & NVH & NVH group \\
\hline Electronics & $\begin{array}{c}\text { FET } \\
\text { durability }\end{array}$ & & $\begin{array}{l}\text { Risk } \\
\text { (FMEA) }\end{array}$ & Electronics \\
\hline $\begin{array}{c}\text { Motor } \\
\text { Supplier }\end{array}$ & $\begin{array}{c}\text { Motor } \\
\text { parameters }\end{array}$ & & $\begin{array}{l}\text { Motor } \\
\text { speed }\end{array}$ & $\begin{array}{c}\text { Motor } \\
\text { Supplier }\end{array}$ \\
\hline
\end{tabular}

Figure 2. SIPOC example

To better understand how the current process works, the process map was developed as illustrated in Figure 3.



Figure 3. Process map example

In the Measure stage, a Matlab model was developed for data measurement. Baseline performance was established using statistical analysis based on the simulation result. In the Analyze stage, a Cause-and-Effect diagram was used to find the potential causes for motor speed variation. Design of Experiment (DOE) ${ }^{2}$ was used to identify the main contributing factor to the motor speed variation as shown in Figure 4. 


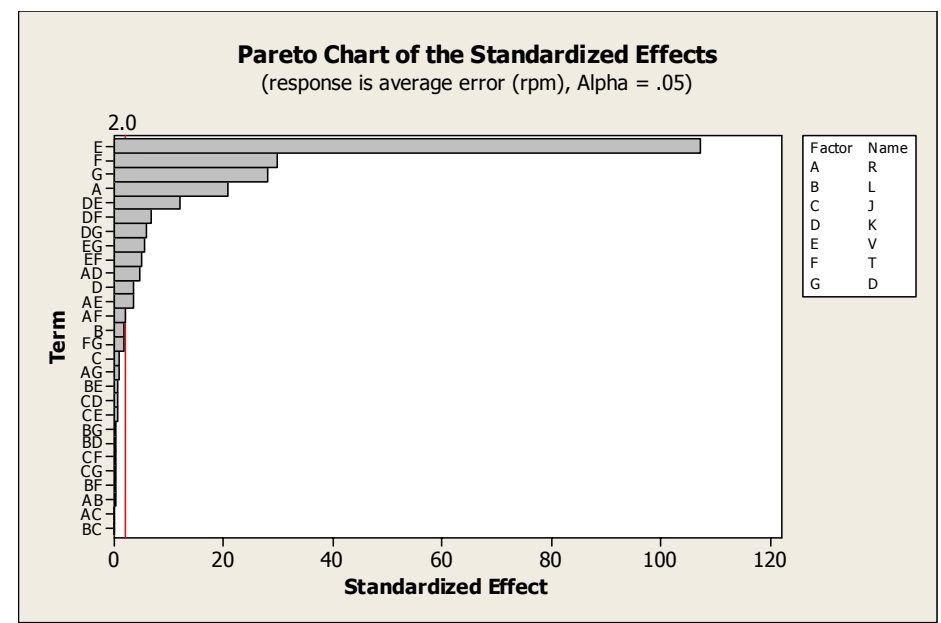

Figure 4. Result from DOE

Based on the DOE result, the Response Surface Method (RSM) ${ }^{2}$ was used to find a solution to reduce the speed variation. The improvement of the new design was validated using simulation as illustrated in Figure 5.

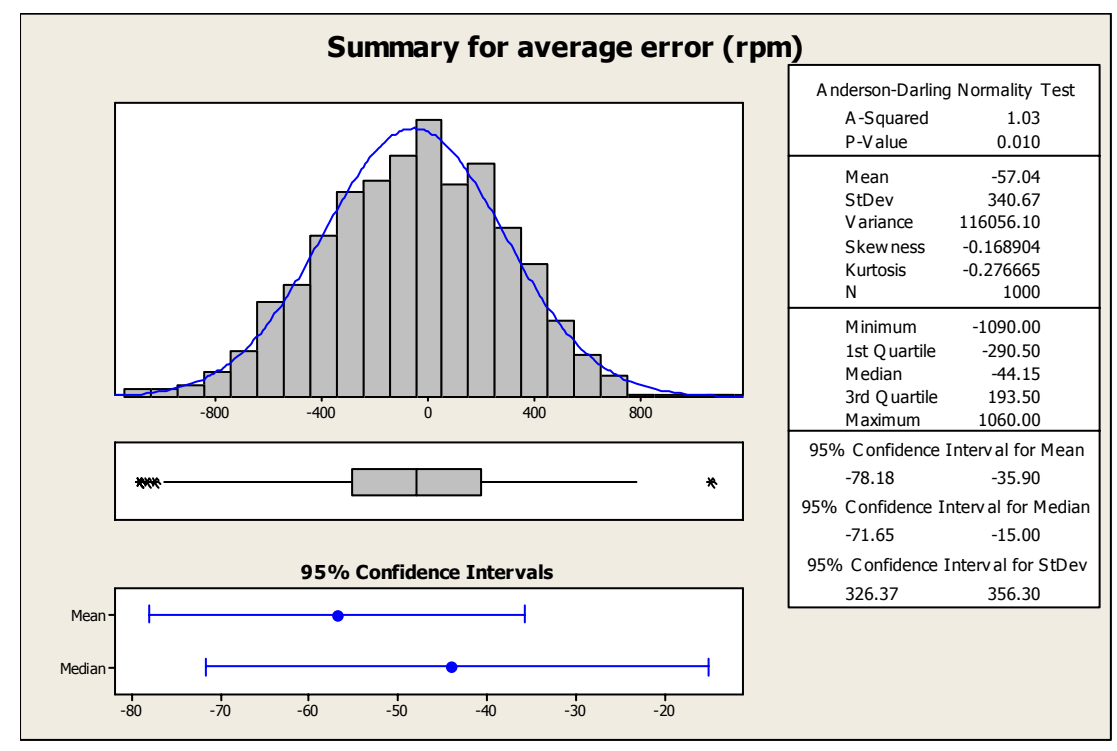

Figure 5. Statistic analysis of the improved process

The new process was standardized in the Control stage to maintain the improvement. Through this example, the students were exposed to many Six Sigma concepts and tools.

\subsection{The course project as a Six Sigma project}

The objectives of the Six Sigma project are:

- To reduce the gap between what the students learn in school and what they face in the real world;

- To expose the students to the Six Sigma process;

- To have the student learn some of the commonly used engineering tools by using these tools in their projects;

- To let the students manage their projects using project management tools so they are better prepared for their senior design projects; 
- To have the students apply the knowledge they learned in instrumentation to a practical product.

To achieve these objectives, a product designed by students from the previous semester was presented first. The product was a low cost, intelligent traffic control system $^{6}$ that can adjust the time delay between the green traffic lights at intersections based on the weather/road conditions. The basic idea was to extend the yellow light duration when the road is icy/wet or it is dark to give the drivers more time to react.

For the baseline design, a temperature sensor, a humidity sensor, and a light sensor are used to detect temperature, humidity, and light intensity. The signals are amplified, filtered and converted to digital signals. The digital signals are transmitted wirelessly to a central controller, where digital signal processing is performed. The output from the controller is a delay time.

The original course project was designed such that the students could use what they learned in the instrumentation class to build a prototype. For example, the students need to know how to convert a resistance change into a voltage using a constant voltage potentiometer or a Wheatstone bridge; they need to know how to build an anti-aliasing filter before the signals are fed to an analog-to-digital converter; they need to know how to program a wireless communication system to transmit the data to a remote location; and they need to know how to design a digital filter. All these are important skills that the students are must learn from this class. To change this project into a Six Sigma project, the students were not just given the design specifications as is typical for a course project. Instead, they were asked to first analyze the design done by the students in the previous semester. Teams consisting of three to four students were formed. The teams were required to identify an area for further improvement. For example, two teams identified cost reduction as their focus area for improvement; one team chose optimization of the signal conditioning circuit; another team identified fault detection as the area for improvement. Over a period of seven weeks, the students first defined their project charter and their metric for performance. The performance metric was chosen to establish the baseline performance. A process mapping was developed using SIPOC, and a CTQ tree was created to better understand the customer need. QFD ${ }^{7,8,9}$ was used to translate the VOC to a design requirement document before designing the system. They created a Work Breakdown Structure (WBS) ${ }^{10,11}$ and a Critical Path Method (CPM) ${ }^{10,11}$ for the management of their project. The students then focused on the identified areas for improvement of the product. Test data was collected for statistical analysis. They tried to identify the root cause of the problem they were analyzing using the Cause and Effect diagram and FMEA ${ }^{12,13,14}$. Design improvement ideas were proposed and tested. Detailed documentation of their Six Sigma project was created to make sure that others could further analyze and improve their design and would not have to "reinvent the wheel". The students learned first hand how important documentation is: they struggled in the beginning to understand the baseline design due to poor documentation by the students from the previous semester.

There are many tools that could be and were used throughout the Six Sigma project. The students learned some simple tools such as SIPOC, CTQ, Cause-and-Effect diagram, WBS, CPM, and VOC from the example that was presented to them before they started their actual project. Other tools such as FMEA, FTA ${ }^{15,16}$, QFD were further illustrated by 
walking through some examples and working with the students to apply these tools to their project. Some of these tools typically require formal training and seminars when used in industry. Because of the short duration and the large amount of tools involved, the goal is the breadth rather than the depth. The goal is to have the students exposed to these tools so that they will be able to make a decision on what tools to use for a particular problem. Once familiar with a given tool, it will be easier for them to learn the tool better in industry if necessary.

Project management is an important part of a Six Sigma project. In previous semesters, students tended to do most of the project-related work near the end of the semester. The project management part of Six Sigma helps the students to conduct their project at an even pace. Instead of working in the "fire-fighting" mode near the end of the semester, they spent more time preventing fires from happening early on. The faculty member kept track of teams' progress by holding weekly review meetings. The students also learned other basic skills such as teaming voting, writing meeting minutes, brainstorming, and using affinity diagrams. The students were required to do a demonstration for their prototype, give a presentation, and write a final report for their project.

\subsection{Assessment}

The assessment of teaching Six Sigma consisted of two parts: one for the students and one for the effectiveness of the teaching Six Sigma.

For the assessment of the projects, each team was evaluated based on the technical content of their project, the use of Six Sigma tools, teamwork, project management, weekly review meetings, the prototype demonstration, the presentation, and documentation. To encourage students to get involved in every aspect of their project and work together effectively as a team, one project-related problem was included in the final exam. The students were told about this before they started their project. A typical problem can be: "What are the purposes for the following tools: QFD, CPM, FMEA, FTA, CTQ, SIPOC, Fishbone diagram, VOC, DOE, RSM, MSA?" Based on the results from the final exam, most of the students had a good understanding of the Six Sigma process and the various tools. The students were also asked to evaluate their teammates. This peer evaluation result was used to determine individual scores for each student.

The assessment of the teaching of Six Sigma was done by an informal anonymous survey. The students were asked to comment on what could have been done differently and what was done well for the teaching of Six Sigma. In addition, they gave numerical scores (on a scale from 1-10, 10 being the best) and comments to the following six questions:

1. How likely will you use Six Sigma tools in your future projects?

2. Is the Six Sigma approach effective in improving the existing design?

3. Did we spend enough time in class/lab to learn Six Sigma?

4. Were the weekly meetings helpful and effective?

5. Do you prefer to work on a Six Sigma project over a regular project?

6. Overall evaluation for the usefulness of the Six Sigma project

The average score for these questions are: 
Table 1. Evaluation of the Six Sigma teaching

\begin{tabular}{|c|c|c|c|c|c|c|}
\hline Question & 1 & 2 & 3 & 4 & 5 & 6 \\
\hline Score(1-10) & 8.5 & 9.2 & 6.3 & 8.7 & 7.6 & 8.5 \\
\hline
\end{tabular}

Some of the comments by the students are very positive:

"I think this is an awesome project. It is good to learn the methodology to solve huge problems on a small scale like this."

"Great for future projects!"

"Project management is very helpful."

"We got to see how business' operations work in the real world."

Some are negative:

"Too many things taught in a short period of time."

One student had an interesting observation about the Six Sigma project:

"I learned it is easier to build than to fix."

The last comment provides an answer to the concern: "Would the students be able to learn what they need to learn from an instrumentation course by doing a Six Sigma project?"

\section{Lessons learned}

There are several things that were learned from the experience of teaching Six Sigma in a course project.

$\diamond$ A good sample Six Sigma project is helpful for the students to understand the DMAIC process.

$\diamond \quad$ A good guideline for the project is helpful for the students. Because the main ideas of Six Sigma were covered in one lab class by going through a Six Sigma project example, some students got confused about what to do next. As a result, a one page guideline was created for next semester's Six Sigma project.

$\diamond \quad$ The peer evaluation should have a requirement that no two students can have the same score. Some teams had perfect scores for everybody, even though it was clear from the weekly review meetings that individual contributions were quite different.

$\diamond$ Students learn the tools better by walking through simple examples with them.

$\checkmark$ Teamwork needs to be emphasized; otherwise some students don't make much contribution to the project and expect to pass. Many students are taking multiple courses, some tried to have one student to do most of the work for one project so others can work on projects in other classes. This kind of "strategic planning" may help the students get better grades, but it is not the best way to learn knowledge. Instead, we would like to have the students learn to use project management tools to better manage their team projects.

\section{Conclusions}

A learning-by-practicing method was applied to an instrumentation course project for teaching the Six Sigma concept to junior level Electronic Engineering Technology students. The students learned to use many common Six Sigma tools during the project. This better prepared them for the senior design projects and for their jobs. Due to the short duration of the project, we aim for breadth rather than depth in learning the Six 
Sigma methodology. After this project, the students will have a general understanding of Six Sigma and will be able to make decisions on what tools to use for a particular problem in each of the DMAIC stages. Their exposure to the tools and processes will make them better prepared to study a particular topic or tool in more depth later if necessary for their career. Through the Six Sigma project experience, the students realized that technical expertise is just one part of the successful product design effort. The emphasis on the Voice of Customer is crucial when a commercial product is designed.

The Six Sigma approach can be used in many other course projects and the senior design projects. The versatility of the skill set learned in this approach is applicable to many problems that the students come across in both their professional and personal lives, and thus is important for a well rounded educational experience. Early exposure to the commonly used engineering tools is beneficial to the students. After several times of applying the Six Sigma methodology, they will become more confident in using Six Sigma. It is our hope that the experience in teaching Six Sigma presented in this paper provides some useful information for others who want to teach Six Sigma to their Electronic Engineering Technology students.

\section{References}

1. "Six Sigma: The Breakthrough Management Strategy Revolutionizing the World's Top Corporations", M. Harry, and R. Schroeder, Doubleday, New York, 2000.

2. "The Certified Six Sigma Black Belt Primer", B. Wortman, W. R. Richdson, G. Gee, M. Williams, T. Pearson, F. Bensley, J. Patel, J. DeSimone, D. R. Carlson, Quality Council of Indiana, West Terre Haute, IN, December, 2001.

3. "Lean Six Sigma as an Improvement Tool in Academia", R. Coowar, S. Furterer, T. Akinrefon, A. Battikhi, A. Ferreras, K. Gibson, R. Lakkoju, and K. Meza, ASEE, 2006-1504.

4. "A Course Project With A Focus On Product Development Process", W. Zhan, B. Zoghi, and R. Fink, ASEE Conference, 2007.

5. "Robust design for Pulse Width Modulation control using Six Sigma tools", W. Zhan, Proceedings of the 2007 IEMS Conference, Florida, 2007.

6. Student course project report, 2006.

7. "Joint Requirements Engineering", G. Herzwurm, S. Schockert, and W. Mellis, 2000.

8. "House of Quality (QFD) in a Minute", 2nd ed., C. N. Madu, 2nd ed., Chi Publishers, May 1, 2006.

9. “Step-by-Step QFD: Customer-Driven Product Design", 2nd ed., J. Terninko, 2nd ed., CRC, July 31, 1997.

10. "Project Management, A System Approach to Planning, Scheduling, and Controlling", H. Kerzner, 1995, $5^{\text {th }}$ ed. New York: Van Nostrand Reinhold.

11. "Project Management, A System Approach to Planning, Scheduling, and Controlling", H. Kerzner, 9th ed., Wiley, December 2, 2005.

12. "Procedures for Performing a Failure Mode, Effects and Criticality Analysis", MILSTD-1629.

13. "Guidelines for Failure Mode and Effects Analysis (FMEA), for Automotive, Aerospace, and General Manufacturing Industries”, D. Press, CRC, March 3, 2003. 
14. "Failure Mode and Effect Analysis: FMEA from Theory to Execution", D. H. Stamatis, 2nd ed., ASQ Quality Press, June 2003.

15. "Fault Tree Analysis Application Guide", D. J. Mahar, The Center, 1990.

16. "Fault Trees", N. Limnios, Wiley, 2007. 